\title{
The Relationship Between the Teaching and Scientific Research in the Independent College
}

\author{
LIU Shun-qin
}

\author{
Xiamen University Tan Kah Kee College ,Zhangzhou 363105,China. \\ pytxlx@163.com
}

Keywords: Idependent college, Udergraduate, research, Pofessional ranks, Dissertation

Abstract. With the continuous development of independent colleges, it has become a hot discussion whether to do scientific research and how to do scientific research.

\section{论独立学院本科教学与科学研究之间的关系}

\author{
刘顺琴 \\ 厦门大学嘉庚学院, 福建 漳州 \\ pytxlx@163.com
}

关键词: 独立学院, 本科教学, 科学研究, 职称评定, 毕业论文

\begin{abstract}
摘要: 独立学院成立之初, 受到师资、办学经验以及地理位置等诸多因素的限制, 科研力量 普遍薄弱。随着独立学院完整办学的实现, 薄弱的科研力量成为制约其发展的瓶颈。本文从 本科教学的重要性、科学研究的必要性、教学与科研的关系、科研与职称评定的关系和科研 与毕业论文指导工作之间的关系等五个方面阐述了本科教学与科学研究之间相互依存、相互 促进的关系，充分论证了 “教学与科研并重” 是独立学院可持续发展必由之路的观点。
\end{abstract}

\section{1. 引言}

部分实施本科以上学历教育的普通高等学校与国家机构以外的社会组织或者个人合作， 利用非国家财政性经费, 共同兴办实施本科学历教育的独立学院, 成为我国高等教育由精英 教育向大众教育转型的重要载体 $[1]$ 。独立学院发展至今, 学院数量已将达到 300 所,在高校人才 培养中起着举足轻重的作用. 虽然独立学院一般定位于应用型本科院校, 主要培养应用创新 型人才和高素质的普通劳动者, 但是 “人才培养、服务社会、科学研究” 始终是高校办学的 三大宗旨, 独立学院既然实施本科教育, 该目标就同样适用, 只有教学、科研的最终成果为 社会需要和接受, 高校的价值才能得以实现, 成本才得以补偿[2]。钱伟长院士也指出： “教 学没有科研作为底蕴, 就是一种没有观点的教育, 没有灵魂的教育” [3]。大学在产生之初, 即在古希腊、罗马时代, 教学与科学研究浑然一体, 教学过程和研究过程密不可分。然而, 部分独立学院成立之初, 受到办学经费、办学师资、办学经验以及地理位置普遍偏僻等诸多 因素的限制, 专业实验室建设和科研制度建设均未得到重视和完善, 科研力量普遍薄弱。但 科学研究作为提升高等院校教育质量和层次的关键 [4-7], 必将成为制约独立学院进一步发展 的瓶颈。因此, 独立学院必须实行 “教学与科研并重” 的发展策略。但由于独立学院在办学 方式和办学经验方面的特殊性, 可以在教学与科学研究的问题上采取循序渐进、逐步过渡的 
方式, 即先重视教学, 在教学稳定之后再鼓励和扶持学校的科学研究力量, 最终实现教学与 科研共同发展、互相促进的目标。

\section{2. 本科教学的重要性}

教学工作是学校的最本源也是最重心的功能。教学工作对所有的高校都非常重要, 独立 学院更是如此。在科研力量相对比较薄弱的现实背景下, “良好的学风, 规范而高质量的教学” 成为独立学院目前的核心竞争力。教书育人是教师的天职, 保证每一堂课的质量是独立学院 的立身之本。每堂课四十五分钟, 把每门课的听课学生数和课时做个简单的乘法, 就组成了 一组组沉甸甸的庞大数字，这些数字代表了构成生命的唯一要素：时间，而且大量的时间。 因此, 不断提升教学质量是高等院校的首要任务。具体可以从以下几方面开展工作：（1）广 泛开展教学探讨; (2) 加大教学改革力度; (3) 落实本科教学质量工程建设。在计算机网 络高速发达的现代社会,教学改革也是提升教学水平的重要举措。

\section{3. 科学研究的必要性}

前面提到“科学研究”是高校办学的三大宗旨之一, 可见科研同样是高校工作的重要内容。 做好科研可以同时实现两个重要目标：（1）更好地完成人才培养;（2）更好地服务社会。 高校尤其是本科院校应该提倡培养具有较强创新意识的高级专门人才, 独立学院也不例外。 这就要求高校教师自身需要拥有较强的创新意识和能力, 而这种能力不会凭空出现, 自然生 成。无论是教师还是学生, 其创新能力的提升只能来源于科学研究的实践过程。其次, 从服 务社会的角度出发, 高校为社会输送高素质人才, 只完成了服务社会的一个内容, 还有另一 项重要内容: 高校还需成为整个社会的核心科研团体力量, 去关注、研究和解决各个行业发 展中遇到的难题, 特别是技术难题, 切实为区域发展排忧解难, 提供社会经济发展的驱动力, 最终实现服务社会的功能。

\section{4. 本科教学与科学研究之间的辩证关系}

教学与科学研究首先是矛盾的。对社会和学校而言, 教学与科研在价值评价方面, 经费 的投入方面是对立的。由于工作性质和工作成果的截然不同, 使得教学成果和科研成果很难 在价值评价上达到平衡。另外学校的运转经费有限, 所以在重视科研成果奖励的同时就必然 忽视教学成果; 反之, 如果在教学中设立太多奖励就没有更多的经费去支持科学研究。对于 教师而言, 现代独立学院是大众化教学的产物, 独立学院要生存和发展就必须不断扩大招生 规模, 造成师生比例严重偏低, 师资力量严重不足。独立学院教师的教学工作量远远高于公 办本科院校的教师, 在这种情况下, 教师很难再抽出精力去搞科研。即便有少数教师有做科 研, 科研做得好的教师, 却很难拿出更多的时间和精力用于提高教学质量。

但是, 教学与科学研究也是统一的, 是辩证的关系。实际上, 就高等院校的发展而言, 本科教学与科学研究同等重要, 并且相互依存, 相互促进。主要体现在以下两个方面。第一, 教学实践过程蕴含大量的研究课题, 是科研灵感的重要发源地。化学发展史上元素周期律的 发现就是一个典型的例子。门捷列夫作为一名大学教师, 其初衷只是为了编写一本系统性较 强的《无机化学》讲义, 以便于学生理解和记忆。因此, 想方设法地寻找无机元素之间的内 在联系和规律, 经过二十多年的不解努力, 竟与元素周期律不期而遇, 一跃成为伟大的化学 家。化学即使发展到今天, 仍然可以从教学过程中发现一些新课题。比如原子结构从最初的 蛋糕布丁模型发展到波动力学模型, 仍然有十一个元素的核外电子排布得不到合理的解释, 这就意味着该理论仍然存在缺陷和不足, 如果有足够的兴趣, 这就是一个很好的研究课题。 其他的学科发展和教学中, 同样会有类似的例子。第二, 科学研究能够为教学创新带来强大 的驱动力。经常从事科研活动, 能够使教师始终关注前沿动态, 有效促进专业知识的更新, 
保持教师学科领域知识结构的先进性。教师还能经常把科研内容和科研成果引进课堂, 让学 生更加形象和具体地体会到知识的实用性和创新的乐趣, 从而使课堂教学更加生动、活泼和 富有鬼丰力。

\section{5. 科学研究与教师职称评定之间的关系}

职称评定在独立学院的整体发展和教师的个人发展中的重要性不言而喻。高校的发展, 离不开教师队伍的稳定性和队伍质量的不断提升, 自然就离不开教师的职称评定。职称评定 对学术论文提出了明确要求, 因此教师必须开展科研活动才能实现职称的不断提升。但同时 我们又应该清醒地认识到高校教师绝不能仅仅为了职称评定而开展科学研究。

如果仅以职称评定作为科研的出发点和落脚点, 极易导致两个不良后果：（1）缺乏整体 规划, 科学研究容易失去长远目标; (2)为发表论文而做科研, 科学研究失去服务社会的原始 功能, 缺失原始驱动力, 科研成果质量严重下滑。如果仅仅局限于职称评定的论文数量和级 别要求, 从事科研活动的主体将缺乏真正的科学理想与追求, 也就失去了科学研究的长远目 标, 使得本来可以有更好的学术前途的教师停滞不前。另外, 过分地追求科研在职称评定中 的作用，容易造成教师的功利心理，往往会给科研成果的发表造成时间上的紧迫性。以论文 发表为例, 同样的一篇学术论文, 如果时间充裕, 教师可能会选择级别较高的期刊投稿, 这 样就更有可能得到高水平审稿专家的意见和指导并根据审稿专家提出的要求对体系进行更加 深入的研究, 但如果时间紧迫, 为了使论文尽快发表, 就有可能选择要求较低的刊物投稿, 这就使得一些科研体系的完整和深入研究无法得以实现, 无形之中降低了科研成果的质量, 科学研究很难取得重大进展。

\section{6. 科学研究与学生毕业论文工作之间的关系}

随着办学模式的过渡和转变, 独立学院完整办学得以实现, 一个直接关系到学生培养质 量的现实问题“毕业生论文指导工作”呈现在办学管理者的面前, 独立学院的稳定发展离不开 毕业论文指导工作的稳定性和可持续性。而毕业论文的指导工作离不开教师的科研, 毕业论 文的完成过程完全可以融进教师的科研项目当中, 既可以让学生了解专业所学最前沿的课题, 对专业知识有更充分完整的认识, 也可以让老师利用学生的精力完成一些比较简单的工作, 让老师提高科研的效率, 甚者老师可以利用所指导的学生构成一个科研小团队。团队的学生 如果在社会中担任要职, 也有可能为老师带来新的科研课题。因此, 独立学院必须大幅度提 升本院专职专任教师在毕业生论文指导工作中的所占份额和整体科研实力, 进一步减弱毕业 论文工作对外界师资力量的依赖性。同时，通过有效的经费管理制度建设实现合理的经费资 源整合, 迅速大幅度提升独立学院整体的科研支持力度, 持续地调动独立学院本院教师指导 毕业论文的积极性和主观能动性。从而确保学生的培养质量和独立学院的可持续发展。

\section{7. 教学和科研管理}

教学和科研管理是对教学活动和科研活动进行过程中的管理, 只有科学的管理才能带来 最优的效益。独立学院发展至今, 教学管理一般从教务管理出发, 再到各个系部, 至今已经 比较成熟。而在科研管理方面, 由于缺乏经验和一直以来重教学轻科研的工作重心, 每个教师 的教学工作量偏大, 个体难以独立成为科研主力, 每个系部的教师也难以自发形成有效的科 研团队, 这就需要独立学院从整理出发, 建立科研部, 结合国家政策, 参考其他高校, 再根 据独立学院自身的特点制定相关的科研管理政策(比如,科研项目立项原则, 申请立项程序, 立 项项目在研情况检查, 项目档案管理, 科研经费管理, 科研成果管理,奖励政策等)。多设立 校级项目，鼓励老师从校级项目开始，再申请国家项目和企业提供的横向项目。 
综上所述, 本科教学是独立学院的首要任务, 是科学研究重要的灵感发源地。科学研究 是高等院校办学另一重要内容, 是促进教学改革和创新的驱动力。教学与科研相互依存, 相 互促进, 缺一不可。因此, “教学与科研并重”是独立学院可持续发展的必由之路。

\section{References}

[1] Gu Zaiqiu, Yu Fu. Exploration and practice of management innovation in Independent College, Modern Science Education, volumn. 2.pp.152-154, 2010.

[2] Wang Yong. Value chain analysis of cost management in Colleges and Universities, Education and Economy ,volumn.4.pp.52-56,2011.

[3] $\mathrm{Pu}$ Chiwu, Yang Qiyun, Xu Kefei. Combining scientific research projects to improve the quality of experimental teaching, Research \& Exploration in

Laboratory, volumn.29(7).pp.270-271, 2010.

[4] Qin Juan, Yuan Qiping. Set up a platform for scientific research and Practice

[5] Training innovative talents in telecommunications and communications, Laboratory Science, volumn.5.pp.12-14,2009.

[6] Cao Xiaoqun, Liu Xin. Combining with scientific research to carry out students' design experiment, aboratory Science, volumn3.pp.135-136,2006.

[7] Qu Xiaobo. Promoting teaching by scientific research and improving the quality of talent training, Journal of Changchun University of Traditional Chinese Medicine, volumn 23(2).pp. 89,2007 .

[8] Ge Wenjun. Some thoughts on the promotion of scientific research in Colleges and Universities ,Journal of Harbin University ,volumn. 28(9). pp.1-3,2007. 